\title{
Consultations in primary care for symptoms attributed to electromagnetic fields - a survey among general practitioners
} Anke Huss* and Martin Röösli

\author{
Address: Department of Social and Preventive Medicine, University of Berne, Finkenhubelweg 11, 3012 Berne, Switzerland \\ Email: Anke Huss* - ahuss@ispm.unibe.ch; Martin Röösli - roeoesli@ispm.unibe.ch \\ * Corresponding author
}

Published: 30 October 2006

BMC Public Health 2006, 6:267 doi:10.1 186/147|-2458-6-267

This article is available from: http://www.biomedcentral.com/I47I-2458/6/267

(C) 2006 Huss and Röösli; licensee BioMed Central Ltd.

This is an Open Access article distributed under the terms of the Creative Commons Attribution License (http://creativecommons.org/licenses/by/2.0), which permits unrestricted use, distribution, and reproduction in any medium, provided the original work is properly cited.
Received: 22 August 2006

Accepted: 30 October 2006

\begin{abstract}
Background: Five percent of the Swiss population attribute symptoms to electromagnetic fields (EMF). General practitioners (GPs) might play a key role in recognising an emerging health risk, since they are the first to observe and follow up persons who attribute symptoms to EMF. It is unclear to what extent EMFs have become an issue in general practice and which experiences GPs report from the consultations.
\end{abstract}

Methods: We conducted telephone interviews in a random sample of GPs in Switzerland in order to assess the frequency of consultations in primary care due to EMF and the GPs' experience with these patients.

Results: 342 general practitioners were interviewed, corresponding to a response rate of $28.2 \%$. $69 \%$ of the GPs reported at least one consultation due to EMF, but GPs with a certificate in complementary medicine were much more likely to report EMF consultations. The median of EMF consultation numbers within one year was three. An overview of the most recent EMF-related consultation per GP yielded sleep disorders, headaches and fatigue as the most often reported symptoms and mobile phone base stations, power lines and the own use of mobile phones as the main EMF sources suspected to be associated to symptoms. GPs judged the association between EMF and the symptoms to be plausible in $54 \%$ of the cases. There was no combination of symptoms and EMF sources that was remarkably and consistently judged to be a plausible cause of the symptoms.

Conclusion: In our survey, GPs often judged the association between the health problems and the suspected exposure to be plausible. This plausibility assessment seems to be based on grounds of preventive positions in a situation of scientific uncertainty. More research effort is needed to obtain more insight on a potential association between long term EMF exposure and unspecific symptoms.

\section{Background}

Everyone is exposed to a complex mixture of electric and magnetic fields at many different frequencies. In the scientific literature and in the media, increasing attention is paid to the potential adverse effects of electromagnetic fields (EMF) on human health, especially since the introduction of modern telecommunication technologies. Regarding radiofrequency EMF, such as those from base stations or mobile phones, the Stewart Report concluded in 2000 that "the balance of evidence to date suggests that 
exposures to RF radiation below guidelines issued by the National Radiological Protection Board (NRPB) and the International Commission on Non-Ionizing Radiation Protection (ICNIRP) guidelines do not cause adverse health effects to the general population" [1]. In 2004, a review of 26 reports on mobile phones and health by the NRPB concluded that exposure towards radiofrequency EMFs causing adverse health effects remained unproven. There was, however, scientific evidence suggesting subtle biological effects [2]. The World Health Organization summarised in a report on low-frequency exposures, such as from household or railway power supply, that "many health outcomes ranging from reproductive defects to cardiovascular and neurodegenerative diseases have been examined, but the most consistent evidence to date concerns childhood leukaemia" [3]. The International Agency for Research on Cancer classified low-frequency magnetic fields as possibly carcinogenic to humans based on epidemiological studies of childhood leukaemia [4].

So far, it is unclear to what extent EMFs have become an issue in general practice and which experiences GPs report from these consultations. In 2005, an estimate based on a representative survey yielded that more than half of the Swiss population perceived EMFs as potentially harmful and 5\% attributed symptoms to EMF [5]. Of these affected persons, $13 \%$ reported to having consulted a general practitioner (GP). GPs might play a key role in recognising an emerging health risk, since they are the first to observe and follow up persons who report health problems.

We conducted computer assisted telephone interviews (CATI) on a random sample of GPs in Switzerland in order to assess the frequency of consultations in primary care due to EMF, their experience with these patients as well as their perception of risk related to EMFs.

\section{Methods}

General practitioners in the French and German speaking parts of Switzerland working in primary care practices were eligible for the survey. A random sample was drawn from the address-database of the Swiss Medical Association, stratified by language area.

The survey was announced by a letter beforehand. We interviewed GPs by means of CATI. The time frame was between 15-23 minutes per interview, depending on whether GPs reported having had any consultations about EMF or not. The interviews took place in May and June 2005.

In order to obtain a representative overview over occurring cases, GPs were asked about the most recent EMF case: They were inquired about reported symptoms and suspected EMF sources, an estimation of the plausibility of an association between EMF source and health complaint(s) by the GP and the given advice. They were also asked about the frequency of such consultations. Another part of the questionnaire dealt with the GPs' perception of potential health risks from EMF and their self-reported level and/or need of information. We also asked whether GPs thought that it would be necessary to implement a national or regional interdisciplinary environmental medicine counselling centre. The questions were openly asked with a prepared list for the interviewers in order to avoid suggestion bias.

GPs with a certificate in traditional Chinese medicine or acupuncture (Association of Swiss Practitioners' Societies for Acupuncture and Chinese Medicine, "ASA"), homeopathy (Swiss Association of Homeopathic Physicians, "SVHA"), neural therapy (Swiss Medical Association for Neural Therapy, "SANTH") or anthroposopical medicine (Anthroposophic Medical Association of Switzerland, "VAOAS") were grouped as "complementary-medicine GPs".

We calculated percentages of subgroups of GPs who reported at least one EMF consultation or who believed that EMF, as occurring under everyday conditions, could cause symptoms; 95\% confidence intervals for proportions were estimated with the Wilsons 'score' method [6]. We then evaluated which factors predicted whether GPs reported EMF consultations or that GPs believed that EMF can cause symptoms using multiple logistic regression. We used the same procedure to compare GPs "plausible" case evaluations to "implausible" evaluations. We included in all our logistic regression models sex and age of the GP, whether the majority of the patients of each practice came from "urban or agglomeration", "rural", or "equally urban or rural" areas, self rated information level with regard to health effects from EMF (rather bad, middle, rather good) as well as complementary-medicine certificate (yes versus no). Analyses were performed in STATA 9 (StataCorp, College Station, Texas, USA).

\section{Results}

Of approximately 7200 GPs in Switzerland, we contacted 1328 (18\%). Of these, 375 agreed to the interview, corresponding to a response rate of $28.2 \%$. Thirty-three persons did not fulfil eligibility criteria (not currently practicing as GP) which resulted in 342 completed interviews. The mean age was 52 years (SD 7.7 years, range 36 - 75 ) and $20 \%$ were female (Table 1). Fifty-eight (17\%) of the GPs had at least one certificate in complementarymedicine. These were $8 \%$ with a certificate in traditional Chinese medicine, $7 \%$ in homeopathy, 5\% in anthroposopical medicine and $1.5 \%$ in neural therapy. 
Table I: Demographics of GPs

\begin{tabular}{ll}
\hline & $\mathbf{N},(\%)$ \\
\hline All GPs & $342(100)$ \\
\hline Sex & $275(80)$ \\
Male & $67(20)$ \\
Female & $64(19)$ \\
Age groups (years) & $126(37)$ \\
$<35-44$ & $138(41)$ \\
$45-54$ & $12(3)$ \\
$55-64$ & $124(36)$ \\
$\geq 65$ & $139(4 I)$ \\
Majority of patients comes from rural vs. urban and agglomeration area & $78(23)$ \\
Majority from rural area & \\
Majority from urban or agglomeration area & $74(22)$ \\
Equally urban or agglomeration/rural & $173(5 \mathrm{I})$ \\
GPs self-reported level of information regarding health effects from EMF & $90(26)$ \\
Rather bad & $5(1)$ \\
Middle & \\
Rather good & $284(83)$ \\
Don't know & $58(17)$ \\
GPs with certificate in complementary medicinea & \\
No certificate & \\
With certificate &
\end{tabular}

a At least one of the following: traditional Chinese medicine/acupuncture, neural therapy, homeopathy or anthroposophical medicine

EMF as a reason for at least one consultation in the past were reported by $69 \%$ of all GPs (Table 2). Complementary-medicine GPs were much more likely to report the occurrence of at least one EMF consultation (Table 3) as were those GPs who reported a higher self-rated level of information with regard to potential health effects from EMF.

The majority of their consultations to do with EMFs had occurred within the last year and 19\% of the GPs reported to have had 10 or more such consultations over the course of the last year. Complementary-medicine GPs reported a higher frequency of EMF-related consultations with a median of 10 (interquartile range 3 - 35) compared to non-complementary-medicine GPs with 3 (interquartile range 1 - 5.5). Of 171 GPs who had had their practice for over a decade, half (50\%) reported an increase of the consultation numbers over that time, $43 \%$ reported no increase and 7\% didn't know.

When asked about details of their most recent EMF consultations, symptoms of patients were usually non-specific. Symptoms that were reported more than once included sleep disorders (43\% of cases), headaches (39\%), fatigue (14\%), and a range of other health complaints, such as nervousness, vertigo, difficulties concen-

Table 2: number of EMF consultations.

\begin{tabular}{lcc}
\hline Most recent EMF consultation & $\mathbf{N} 342$ & $\%$ \\
\hline No EMF consultations reported & 105 & 30.7 \\
Reports at least one EMF-consultation & 237 & 69.3 \\
\hline Number of EMF consultations in the last year & & 9.4 \\
0 & 32 & 28.4 \\
$1-4$ & 97 & 10.5 \\
$5-9$ & 36 & 14.0 \\
$10-49$ & 48 & 2.9 \\
$50-99$ & 10 & 1.8 \\
$\geq 100$ & 6 & 2.3 \\
Don't know & 8 & \\
\hline
\end{tabular}

Number (\%) of GPs reporting any EMF-consultation as well as the number of EMF-consultations within the last year. 
Table 3: number and percentage of GPs who reported at least one EMF-consultation, stratified by GP-characteristics.

\begin{tabular}{|c|c|c|c|}
\hline & \% (95\% C.I.) & OR $(95 \% \text { C.I. })^{a}$ & $p^{b}$ \\
\hline all GPs & $69(64-74)$ & & \\
\hline \multicolumn{4}{|l|}{ Sex } \\
\hline Male & $\begin{array}{c}69.5 \\
(63.8-74.6)\end{array}$ & $\begin{array}{c}\mathrm{I} \\
\text { (reference) }\end{array}$ & \\
\hline Female & $\begin{array}{c}68.7 \\
(56.8-78.5)\end{array}$ & $\begin{array}{c}0.79 \\
(0.40-1.56)\end{array}$ & 0.50 \\
\hline \multicolumn{4}{|l|}{ Age group (years) } \\
\hline$<35-44$ & $\begin{array}{c}78.1 \\
(66.6-86.5)\end{array}$ & $\begin{array}{c}\mathrm{I} \\
\text { (reference) }\end{array}$ & \\
\hline $45-54$ & $\begin{array}{c}69.8 \\
(61.3-77.2)\end{array}$ & $\begin{array}{c}0.52 \\
(0.24-1.1)\end{array}$ & \\
\hline $55-64$ & $\begin{array}{c}65.2 \\
(57.0-72.7)\end{array}$ & $\begin{array}{c}0.48 \\
(0.23-1.02)\end{array}$ & \\
\hline$\geq 65$ & $\begin{array}{c}66.7 \\
(39.1-86.2)\end{array}$ & $\begin{array}{c}0.46 \\
(0.1-2.04)\end{array}$ & 0.23 \\
\hline \multicolumn{4}{|c|}{ Majority of patients comes from rural/urban area } \\
\hline Majority from rural area & $\begin{array}{c}73.4 \\
(65-80.4)\end{array}$ & $\begin{array}{c}\mathrm{I} \\
\text { (reference) }\end{array}$ & \\
\hline Majority from urban or agglomeration area & $\begin{array}{c}61.9 \\
(53.6-69.5)\end{array}$ & $\begin{array}{c}0.53 \\
(0.30-0.94)\end{array}$ & \\
\hline Equally urban or agglomeration/rural & $\begin{array}{c}75.6 \\
(65.1-83.8)\end{array}$ & $\begin{array}{c}0.83 \\
(0.4-1.69)\end{array}$ & 0.079 \\
\hline \multicolumn{4}{|l|}{ Self-rated information level } \\
\hline Rather bad & $\begin{array}{c}55.4 \\
(44.1-66.2)\end{array}$ & $\begin{array}{c}\mathrm{I} \\
\text { (reference) }\end{array}$ & \\
\hline Middle & $\begin{array}{c}69.9 \\
(62.7-76.3)\end{array}$ & $\begin{array}{c}1.56 \\
(0.86-2.87)\end{array}$ & \\
\hline Rather good & $\begin{array}{c}77.8 \\
(68.2-85.1)\end{array}$ & $\begin{array}{c}2.49 \\
(1.22-5.1)\end{array}$ & 0.041 \\
\hline \multicolumn{4}{|l|}{ Complementary medicine certificate } \\
\hline None & $\begin{array}{c}63.7 \\
(58.0-69.1)\end{array}$ & $\begin{array}{c}\mathrm{I} \\
\text { (reference) }\end{array}$ & \\
\hline At least one $e^{c}$ & $\begin{array}{c}96.6 \\
(88.3-99.0)\end{array}$ & $\begin{array}{c}16.1 \\
(3.74-69.2)\end{array}$ & $<0.0001$ \\
\hline
\end{tabular}

Percentage of GPs who report at least one EMF consultation, stratified by GP-characteristics. aOdds ratio of reporting at least one EMF consultation after multiple logistic regression (model variables: sex, age group, urban/rural patient collective, self rated information level and complementarymedicine certificate). b ${ }^{\mathrm{p}}$-value of likelihood ratio test after logistic regression. cAt least one of the following: traditional Chinese medicine/ acupuncture, neural therapy, homeopathy or anthroposophical medicine

trating, tinnitus, anxiety, tumours and cardiac arrhythmias (Figure 1). The most often listed EMF sources suspected to be associated with the symptoms were mobile phone base stations (33\% of cases), power lines (14\%) and the use of mobile phones (9\%), but other reported specific sources included e.g. TV or computers, TV- or radio broadcasting stations, cordless telephones or microwave ovens. More general suspected sources included "all EMF sources", "all communication technology EMF", "all EMF from household or train power supplies" (Figure 2). There were no clear patterns between the reported symptoms and their suspected sources.

In most of the cases (77\%), the patients suggested their suspected association between an EMF source and the health complaint in the consultation but, in a minority of cases, only the GP, or both GP and patient (11\% each) thought of EMF as a potential cause of the symptoms. In $1 \%$ of the cases the GPs could not remember who suggested the association. Depending on who reported the association, (GP, patient, both), the most often suspected EMF-sources varied, but not the listed health complaints. For example, if the patient suspected EMF as cause of the health problem, mobile phone base stations were most often suspected as being the cause (37\%), but not the own use of mobile phones $(8 \%)$. If the association was brought up by the GP, mobile phone use was most often suspected ( $24 \%$ of cases) whereas mobile phone base stations were only suspected in $4 \%$. The cases where both GP and patient brought up the association were quite similar to those where the patient alone had brought up EMF as a suspected cause (35\% mobile phone base stations, $8 \%$ 


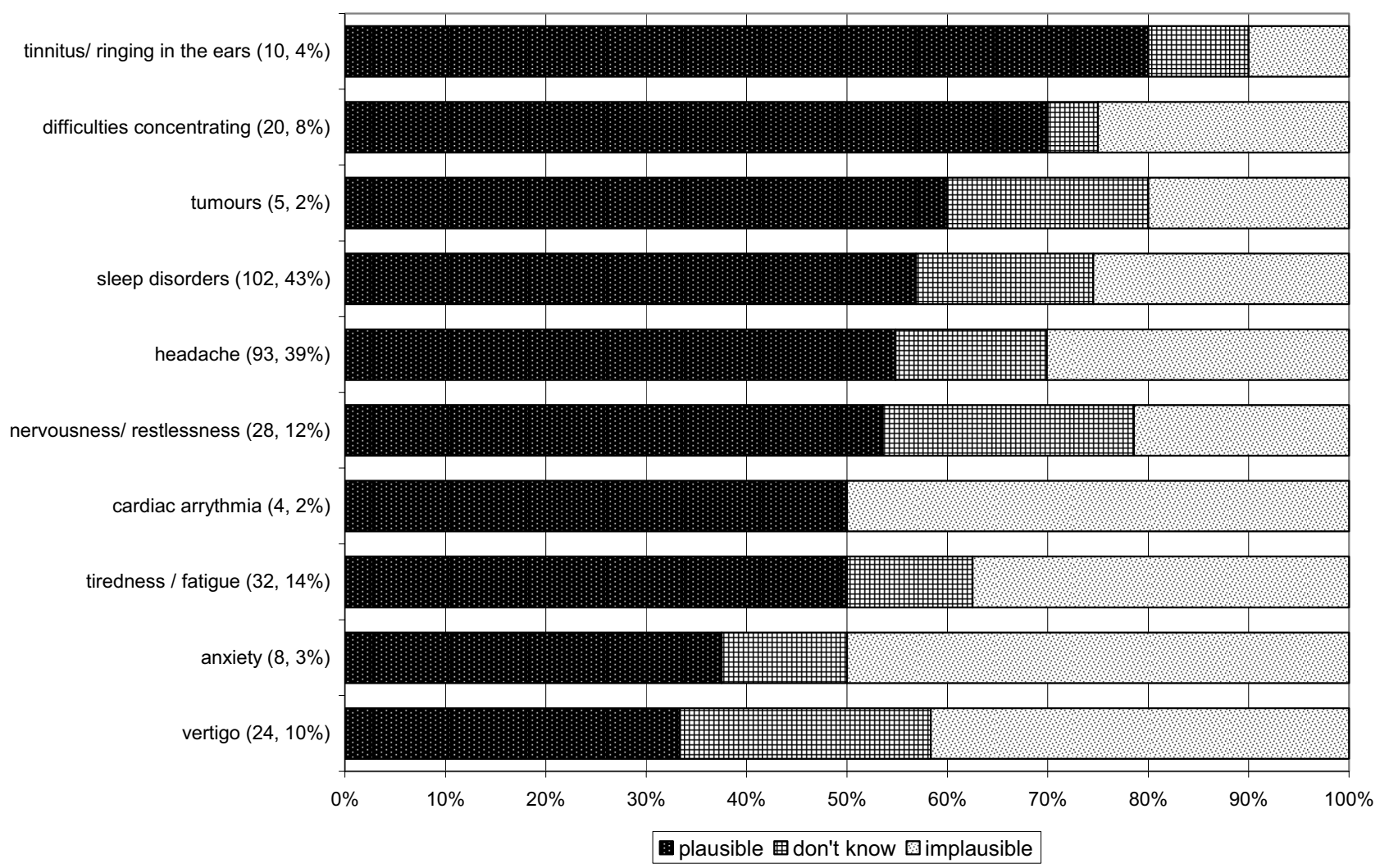

\section{Figure I}

Plausibility rating of association between symptoms and their suspected source, by symptom (absolute number as well as percentage of cases who reported the respective symptom in brackets).

mobile phone use). Power lines as the suspected source were equally often subject of the consultation, independently on who thought about this source first (patients, GPs or both: 14, 16 and 15\%, respectively).

In more than half (54\%) of the cases, the GPs judged the association between EMF and symptoms to be "plausible" and in $29 \%$ to be "implausible". Seventeen percent didn't know. Comparison of "plausible" versus "implausible" ratings showed that age or sex of the GP had no effect on these ratings, but other variables had. Complementarymedicine GPs were more likely to evaluate the association as "plausible", compared to the rest of the GP group (OR: 16.8, 95\% Confidence Interval 3.8 - 74.5). There were some symptoms that were more often thought to be plausible than others, especially tinnitus ( $80 \%$ plausible ratings), concentration difficulties $(70 \%)$ and tumours $(60 \%)$. In contrast, cardiac arrhythmias, anxiety or vertigo were most frequently though to be implausibly connected to EMF sources ( $50 \%, 50 \%$ and $42 \%$, respectively) (Figure $1)$. Of the EMF sources, the own use of mobile phones, electric equipment and cordless telephones - sources in close proximity to the body - were more often judged to be a plausible cause of the symptoms $(82 \%, 75 \%$ and $73 \%$, respectively), compared to other suspected sources. Microwave ovens, TV or radiobroadcast stations as well as mobile phone base stations were most often thought to be implausibly connected to the symptoms (50\%, 43\% and $37 \%$, respectively) (Figure 2). There was no combination of symptoms and EMF sources that was remarkably and consistently judged to be plausible.

The given counsel could be grouped into three main categories: exposure-focussed advice, treatment-focussed advice (e.g. medication or psychosomatic intervention) or no advice. Most often, patients were given exposurefocussed advice with $40 \%$ of the consultations where the patients were advised to get rid of the EMF source, e.g. by 


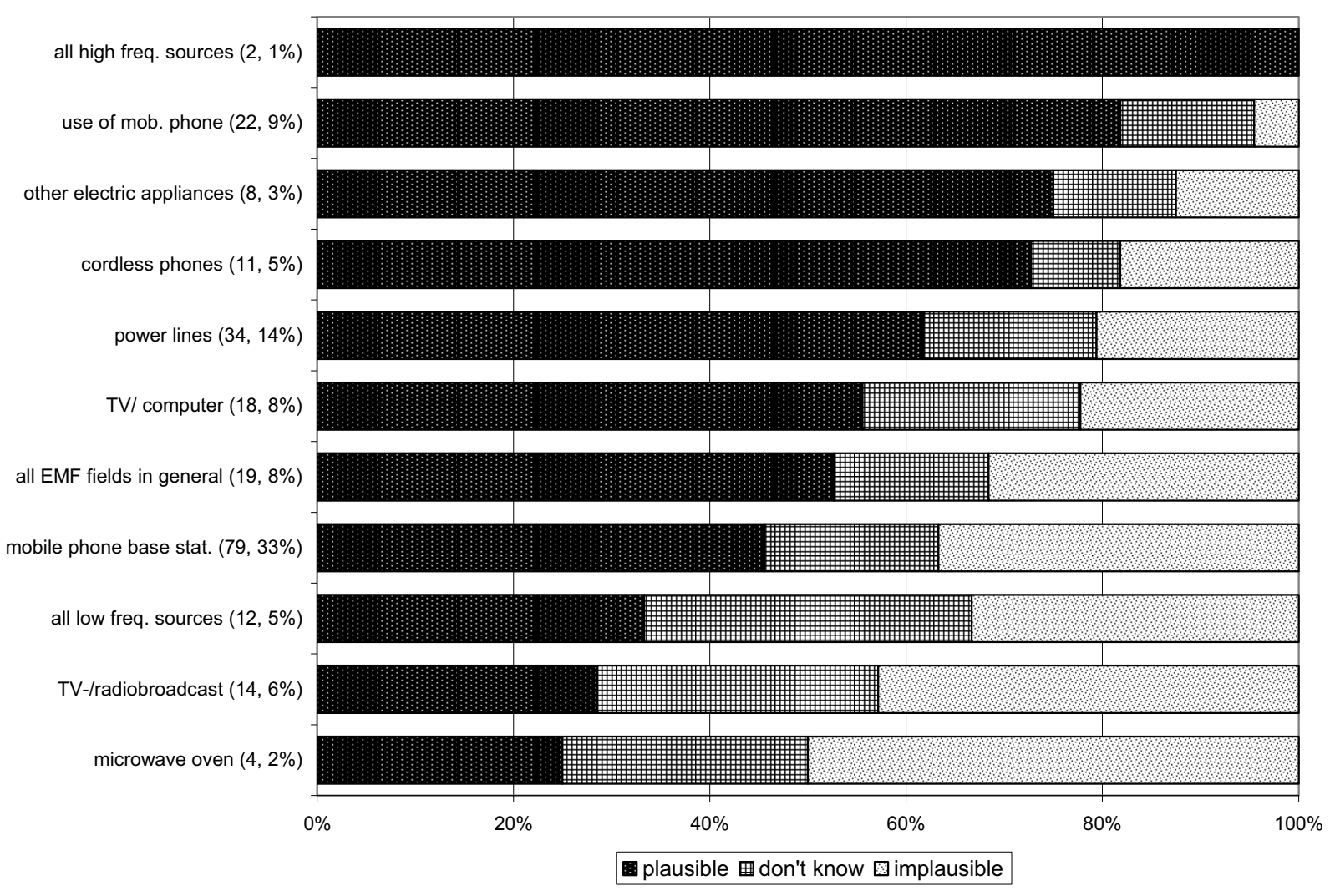

\section{Figure 2}

Plausibility rating of association between suspected source and symptoms, by source (absolute number as well as percentage of cases who suspected this EMF source in brackets).

switching the source off, move house, avoiding the EMF when possible, etc. GPs reported that in $43 \%$ of the patients, an improvement in the state of health had occurred. This was independent of any counselling or therapies administered by them.

Asked in a more general sense, the majority of the GPs (61\%) believed that exposure to EMFs as they occur under everyday conditions, can cause symptoms, $27 \%$ disagreed and $12 \%$ had no opinion. Female GPs were more likely to think that EMFs can cause symptoms, as well as complementary-medicine GPs (Table 4). 14\% of the GPs had considered at least once whether EMF could have been the cause for own symptoms. Again, complementary-medicine GPs were more likely to have had considered EMF as potential cause of symptoms, compared to non-complementary GPs (OR 4.2, 95\% C.I. 2.1 - 9.0).

\section{Discussion}

EMF as a reason for at least one consultation in the past were reported by the majority of the GPs. An overview of the most recent EMF-related consultations in general practice yielded sleep disorders, headaches and fatigue as the most often reported symptoms and mobile phone base stations, power lines and the own use of mobile phones as the main EMF sources suspected to be associated with these symptoms. GPs judged the relation between EMF and the symptoms to be "plausible" in more than half of the cases.

Our response rate of $28.2 \%$ was low. A potential problem could be a selection bias in which concerned or affected GPs were more likely than others to participate. We found an indirect indication for this, because complementarymedicine GP were somewhat overrepresented in our GP 
Table 4: Number of GPs who believed that EMFs can cause symptoms

\begin{tabular}{|c|c|c|c|}
\hline all GPs & $\%(95 \%$ C.I.) & OR (95\% C.I.) $)^{a}$ & $p^{b}$ \\
\hline & $\begin{array}{c}61.4 \\
(56.1-66.4)\end{array}$ & & \\
\hline \multicolumn{4}{|l|}{ Sex } \\
\hline Male & $\begin{array}{c}57.8 \\
(51.9-63.5)\end{array}$ & $\begin{array}{c}\mathrm{I} \\
\text { (reference) }\end{array}$ & \\
\hline Female & $\begin{array}{c}76.1 \\
(64.7-84.7)\end{array}$ & $\begin{array}{c}1.76 \\
(0.89-3.53)\end{array}$ & 0.095 \\
\hline \multicolumn{4}{|l|}{ Age group } \\
\hline$<35-44$ & $\begin{array}{c}70.3 \\
(58.2-80.1)\end{array}$ & $\begin{array}{c}\mathrm{I} \\
\text { (reference) }\end{array}$ & \\
\hline $45-54$ & $\begin{array}{c}66.7 \\
(58.1-74.3)\end{array}$ & $\begin{array}{c}0.76 \\
(0.38-1.53)\end{array}$ & \\
\hline $55-64$ & $\begin{array}{c}55.1 \\
(46.7-63.1)\end{array}$ & $\begin{array}{c}0.65 \\
(0.33-1.29)\end{array}$ & \\
\hline$\geq 65$ & $\begin{array}{c}25 \\
(8.9-53.2)\end{array}$ & $\begin{array}{c}0.22 \\
(0.04-1.2)\end{array}$ & 0.25 \\
\hline \multicolumn{4}{|c|}{ Majority of patients comes from rural/urban area } \\
\hline Majority from rural area & $\begin{array}{c}63.7 \\
(55-71.6)\end{array}$ & $\begin{array}{c}\mathrm{I} \\
\text { (reference) }\end{array}$ & \\
\hline Majority from urban or agglomeration area & $\begin{array}{c}54.7 \\
(46.4-62.7)\end{array}$ & $\begin{array}{c}0.57 \\
(0.33-0.99)\end{array}$ & \\
\hline Equally urban or agglomeration/rural & $\begin{array}{c}70.5 \\
(59.6-79.5)\end{array}$ & $\begin{array}{c}0.85 \\
(0.43-1.68)\end{array}$ & 0.12 \\
\hline \multicolumn{4}{|l|}{ Self-rated information level } \\
\hline Rather bad & $\begin{array}{c}58.1 \\
(46.7-68.7)\end{array}$ & $\begin{array}{c}\mathrm{I} \\
\text { (reference) }\end{array}$ & \\
\hline Middle & $\begin{array}{c}66.5 \\
(59.1-73.1)\end{array}$ & $\begin{array}{c}1.22 \\
(0.67-2.23)\end{array}$ & \\
\hline Rather good & $\begin{array}{c}56.7 \\
(46.4-66.4)\end{array}$ & $\begin{array}{c}0.76 \\
(0.39-1.5)\end{array}$ & 0.27 \\
\hline \multicolumn{4}{|l|}{ Complementary-medicine certificate } \\
\hline None & $\begin{array}{c}54.6 \\
(48.8-60.3)\end{array}$ & $\begin{array}{c}\text { I } \\
\text { (reference) }\end{array}$ & \\
\hline At least one $e^{c}$ & $\begin{array}{c}94.8 \\
(85.9-98.2)\end{array}$ & $\begin{array}{c}13.75 \\
(4.09-46.2)\end{array}$ & $<0.0001$ \\
\hline
\end{tabular}

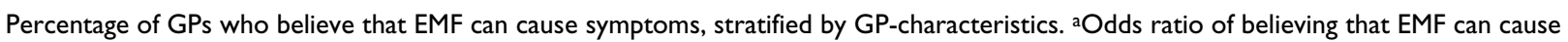
symptoms compared to not believing or being unsure about it after multiple logistic regression (model variables: sex, age group, urban/rural patient collective, self rated information level and complementary-medicine certificate). b $\mathrm{p}$-value after likelihood ratio test ${ }^{\mathrm{C} A t}$ least one of the following: traditional Chinese medicine/acupuncture, neural therapy, homeopathy or anthroposophical medicine.

sample compared to the data base for all GPs. Complementary-medicine GPs were much more likely to report consultations because of electromagnetic fields, to believe that exposure to EMFs as they occur under everyday conditions can cause symptoms and to have considered whether EMF could have been the cause for own symptoms. Weighting the complementary-medicine GPs answers by their relative occurrence in the population of GPs as a whole reduced our estimates only slightly: $67 \%$ instead of $69 \%$ of GPs reported at least one EMF-consultation, $59 \%$ instead of $61 \%$ believed that EMF could cause symptoms and $12 \%$ instead of $14 \%$ had considered EMFs as potential cause for symptoms they had experienced themselves.

In Austria, a written survey on EMF-consultations in general practice yielded very similar results to our survey, although the response rate in the Austrian survey was considerably higher at $49 \%$ [7]. Sixty-eight percent of the GPs reported to have "sometimes" or "frequently" EMF consultations. With respect to risk perception, the GPs were even more concerned about potential health effects from EMF exposure than our Swiss sample.

In a survey based on the Swiss Sentinel system, environmental medicine consultations were assessed over the course of the year 2002 [8]. In this survey, 30\% of the GPs reported at least one environmental medicine consultation within that year, and $2-12 \%$ of these consultations were due to EMFs. This is much lower than the percentage found in our survey, where $58 \%$ of all GPs reported at least one EMF consultation within the last year. One of the reasons for this discrepancy could be a real increase in frequency of these consultations since 2002. In our survey, 
GPs with more than 10 years experience in their practice reported to have observed an increase in EMF-related consultations. Another reason could be that our telephone interview was announced by a letter, which might have led to remembering a case that could otherwise have gone forgotten. This could occasionally have happened in the Sentinella survey where GPs had to fill in a questionnaire once a week. In addition, in the Sentinella survey, GPs were asked about a range of environmental exposures. Exposure towards mobile phones, however, might be considered to be live-style related, rather than to be an environmental exposure. This would also result in reporting fewer cases in comparison to our survey. As in the Sentinella survey [8], the complementary medicine GPs in our survey were less likely than the other GPs to reject an association between environmental exposures and their putative adverse health effects. This may account for the larger number of reported cases and higher attendance of concerned persons in such practices.

Overall, GPs often believed that an association between symptoms and EMF was plausible and frequently advised affected patients to avoid or reduce exposure. Interestingly, a range of international expert panels so far have concluded that the possibility of EMF exposure causing adverse health effects remains unproven [9-17]. This might be considered as a discrepancy. However, one has to take into account that there are two differing concepts behind this apparent discrepancy: the population-based causality evaluation of expert panels, and the individualbased plausibility assessment by the GPs. Single case evaluation is unlikely to provide sufficient evidence to demonstrate a causal relation between exposures and health outcomes, even in those situations where exposures have been shown to be related to health outcomes in epidemiological studies. We took account of these differing concepts by asking for "plausibility" rather than "causality" in our survey. This implicates, however, that GPs might just be prudent in not excluding EMF from a list of potentially possible exposures associated with the health complaints in a situation where causality cannot be addressed directly. Thus, the reported plausibility assessment from the GPs in our survey may be based on grounds of preventive positions in a situation of scientific uncertainty: There are only very few studies that evaluated unspecific symptoms in association with EMF exposure on a long term basis.

There was agreement between scientific expert panels and the interviewed GPs with respect to plausibility ratings according to localisation of EMF sources. The NRPB (2004)[2] reviewed 26 reports from expert panels on EMF and health and summarised that " [...] very low level exposures, typical of base stations, are extremely unlikely to cause any effects on biophysical grounds, whereas local- ised exposures, typical of those from mobile phones, may induce effects [...]." In our survey, EMF emitted close to the body (e.g. mobile phones, cordless phones and electrical appliances) were more often described as "plausible" causes of the health complaints, compared to sources further away (e.g. mobile phone base stations, TV or radio broadcasting stations). Apart from that, there are no obvious patterns that can be extracted from this survey, which would link specific EMF sources to specific health complaints and thus call for a new direction of investigation that is not yet pursued by researchers. However, a pattern would have to be fairly source and symptom specific so that we would be able to pick it up in a survey like ours.

Most of the GPs reported little experience with EMF consultations in general practice: $71 \%$ of all GPs reported to have had fewer than five EMF consultations in the previous year. Of the GPs with few or no EMF consultations in the previous year, the majority still estimated an association between health complaints and EMF sources to be plausible in $52 \%$ of the cases. This makes it unlikely that GPs develop their plausibility assessment based on frequent and repeated experience with EMF-related consultations.

There were some indications that GPs did not feel confident about counselling persons with symptoms attributed to $\mathrm{EMF}$, e.g. 75\% expressed to need more information on the topic for their work as a GP and less than half of the GPs reported to have a standard approach on how to deal with these patients. 53\% would welcome the implementation of a national or regional interdisciplinary environmental medicine counselling centre.

\section{Conclusion}

From the general practitioners' observations no obvious symptom-EMF source pattern could be extracted, which would link a specific EMF source to a specific health complaint and thus call for a new direction of investigation that is not yet pursued by researchers. However, the scientific uncertainty regarding long term effects of EMF on unspecific symptoms is mirrored in the GPs plausibility assessments: The majority of GPs believed that exposure to everyday EMF could cause symptoms, and the relation between EMF and the symptoms of their EMF-related consultations was judged to be "plausible" in more than half of the cases. Thus, we conclude that more research effort is needed to obtain more insight on a potential association between long term EMF exposure and unspecific symptoms.

\section{List of abbreviations used}

CATI - computer assisted telephone interview

EMF - electromagnetic fields 
GP - General Practitioner

ICNIRP - International Commission on Non-Ionizing Radiation Protection

NRPB - National Radiological Protection Board

\section{Competing interests}

The author(s) declare that they have no competing interests.

\section{Authors' contributions}

AH coordinated the study and drafted the manuscript and MR conceived of the study. Both authors designed the study, developed the questionnaire used in the survey, analysed and interpreted the data, revised the draft and read and approved the final manuscript.

\section{Acknowledgements}

We would like to express our special thanks to the GPs who participated in our study, as well as to the GPs who gave valuable comments on the questionnaire in the pretest-phase. We would also like to thank Sabine Bucher and Rolf Wettstein and the whole telephone laboratory crew for the organisation and accomplishment of the interviews.

This survey was funded by the Federal Office of Public Health.

\section{References}

I. Independent Expert Group on Mobile Phones: Mobile Phones and Health. Chairman Sir William Stewart, National Radiological Protection Board, UK; 2000.

2. National Radiological Protection Board: Health Effects from Radiofrequency Electromagnetic Fields - Report of an independent Advisory Group on Non-ionising Radiation. Volume 14, No 22004.

3. WHO: Establishing a dialogue on risks from electromagnetic fields. Edited by: Radiation and Environmental Health and Department of Protection of the Human Environment. Geneva, Switzerland, World Health Organization; 2002:I -66.

4. International Agency for Research on Cancer (IARC): IARC Monographs on the Evaluation of carcinogenic risks to humans: Volume 80. Non-ionizing Radiation, Part I: Static and extremely low-frequency (ELF) electric and magnetic fields. IARC Press Lyon 2002.

5. Schreier N, Huss A, Röösli M: The prevalence of symptoms attributed to electromagnetic field exposure: a cross-sectional representative survey in Switzerland. Soc Prev Med 2006, 5 I:202-209.

6. Newcombe RG: Two-sided confidence intervals for the single proportion: comparison of seven methods. Stat Med 1998, 17:857-872.

7. Leitgeb N, Schröttner J, Böhm M: Does "electromagnetic pollution" cause illness? An inquiry among Austrian general practitioners. Wien Med Wochenschr 2005, 155:237-24I.

8. Huss A, Küchenhoff J, Bircher A, Niederer M, Tremp J, Waeber R, Braun-Fahrländer C, for the Swiss Sentinel Surveillance Network: Are environmental medicine problems relevant in Switzerland? Swiss Med Wkly 2004, 134:500 -507.

9. Ahlbom A, Green A, Kheifets L, Savitz D, Swerdlow A: Epidemiology of health effects of radiofrequency exposure. Environ Health Perspect 2004, I I 2: 174I- 1754.

10. Bernhardt JH: [Electrosmog, cellular phones, sunbeds etc. -adverse health effects from radiation? Health aspects of nonionizing radiation]. Bundesgesundheitsblatt Gesundheitsforschung Gesundheitsschutz 2005, 48:63-75.

II. Feychting M, Ahlbom A, Kheifets L: EMF and health. Annu Rev Public Health 2005, 26:165-189.
12. Kundi M, Mild K, Hardell L, Mattsson MO: Mobile telephones and cancer--a review of epidemiological evidence. J Toxicol Environ Health B Crit Rev 2004, 7:35I-384.

13. Mann K, Röschke J: Sleep under exposure to high-frequency electromagnetic fields. Sleep Med Rev 2004, 8:95-107.

14. Röösli M, Rapp R, Braun-Fahrländer C: [Radio and microwave frequency radiation and health--an analysis of the literature]. Gesundheitswesen 2003, 65:378-392.

15. Seitz H, Stinner D, Eikmann T, Herr C, Röösli M: Electromagnetic hypersensitivity (EHS) and subjective health complaints associated with electromagnetic fields of mobile phone communication--a literature review published between 2000 and 2004. Sci Total Environ 2005, 349:45-55.

16. Sienkiewicz ZJ, Kowalczuk Cl: A Summary of Recent Reports on Mobile Phones and Health (2000 - 2004). Edited by: National Radiological Protection Board. Oxon; 2005:I -34.

17. Rubin G], Das Munshi J, Wessely S: Electromagnetic hypersensitivity: a systematic review of provocation studies. Psychosom Med 2005, 67:224-232.

\section{Pre-publication history}

The pre-publication history for this paper can be accessed here:

http://www.biomedcentral.com/1471-2458/6/267/pre pub

Publish with Biomed Central and every scientist can read your work free of charge

"BioMed Central will be the most significant development for disseminating the results of biomedical research in our lifetime. "

Sir Paul Nurse, Cancer Research UK

Your research papers will be:

- available free of charge to the entire biomedical community

- peer reviewed and published immediately upon acceptance

- cited in PubMed and archived on PubMed Central

- yours - you keep the copyright
BiolMedcentral 